\title{
Particle Size (Sieving) and Enthalpy (Acid Calorimetry) Analysis of Single-Pull K East Basin Floor and Pit Sludges
}

\author{
P. R. Bredt \\ C. H. Delegard \\ A. J. Schmidt \\ K. L. Silvers \\ B. M. Thornton \\ S. R. Gano
}

October 2000

Prepared for Fluor Hanford, Inc.

Work supported by the U.S. Department of Energy under Contract DE-AC06-76RL01830

Pacific Northwest National Laboratory Richland, Washington 99352 


\title{
DISCLAIMER
}

This report was prepared as an account of work sponsored by an agency of the United States Government. Neither the United States Government nor any agency thereof, nor Battelle Memorial Institute, nor any of their employees, makes any warranty, express or implied, or assumes any legal liability or responsibility for the accuracy, completeness, or usefulness of any information, apparatus, product, or process disclosed, or represents that its use would not infringe privately owned rights. Reference herein to any specific commercial product, process, or service by trade name, trademark, manufacturer, or otherwise does not necessarily constitute or imply its endorsement, recommendation, or favoring by the United States Government or any agency thereof, or Battelle Memorial Institute. The views and opinions of authors expressed herein do not necessarily state or reflect those of the United States Government or any agency thereof.

\section{PACIFIC NORTHWEST NATIONAL LABORATORY \\ operated by \\ BATTELLE \\ for the \\ UNITED STATES DEPARTMENT OF ENERGY under Contract DE-AC06-76RL01830}

Printed in the United States of America

Available to DOE and DOE contractors from the

Office of Scientific and Technical Information,

P.O. Box 62, Oak Ridge, TN 37831-0062;

ph: (865) 576-8401

fax: (865) 576-5728

email: reports a adonis osti.gov

\author{
Available to the public from the National Technical Information Service, \\ U.S. Department of Commerce, 5285 Port Royal Rd., Springfield, VA 22161 \\ ph: (800) 553-6847 \\ fax: (703) 605-6900 \\ email: orders@ntis.fedworld.gov \\ online ordering: http://www.ntis.gov/ordering.htm
}

This document was printed on recycled paper.

$(8 / 00)$ 


\section{DISCLAIMER}

Portions of this document may be illegible in electronic image products. Images are produced from the best available original document. 


\section{Summary}

This report presents the results of particle size analyses and calorimetry testing performed on selected single-pull sludge samples collected from the Hanford K East Basin between December 1998 and June 1999. The samples were collected as isolated cores predominantly from areas that had not been previously sampled (e.g., North Loadout Pit, Dummy Elevator Pit, Tech View Pit), or from areas in which the sludge composition had been altered since the last sampling (e.g., Weasel Pit).

Particle size analyses were performed by washing wet sludge samples through a series of four sieves with openings of $250,500,1410$, and $4000 \mu \mathrm{m}$. The loaded sieves were weighed before and after drying to obtain wet and dry particle size distributions. Knowledge of the particle size distribution is needed to design and predict the performance of the systems that will be used to retrieve, transport, and recover sludge. Also, sieving provides an opportunity to observe the components in the sludge. For example, during sieving of the sludge sample from the North Loadout Pit, significant quantities of organic ion exchange beads were observed.

The uranium metal content and the particle size of the uranium metal in the $\mathrm{K}$ Basin sludge will largely determine the chemical reactivity of the sludge. In turn, the designs for the sludge handling and storage systems must be compatible with the reactivity of the sludge. Therefore, acid calorimetry was performed to estimate the uranium metal content of the sludge. For this testing, sludge samples were

dissolved in nitric acid within a calibrated adiabatic calorimeter. The resulting dissolution enthalpy data were then used to discriminate between metallic uranium $(-3750 \mathrm{~J} / \mathrm{g}$ in nitric acid) and uranium oxide $(-394 \mathrm{~J} / \mathrm{g}$ in nitric acid). Results from this testing showed that the single-pull sludge samples contained little or no uranium metal. 


\section{Contents}

Summary

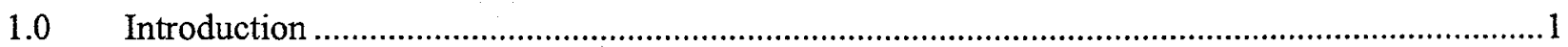

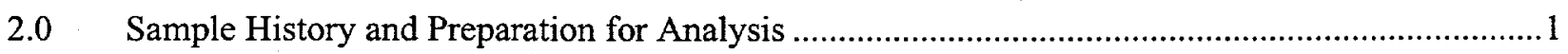

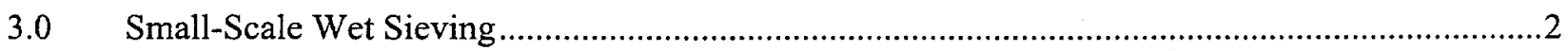

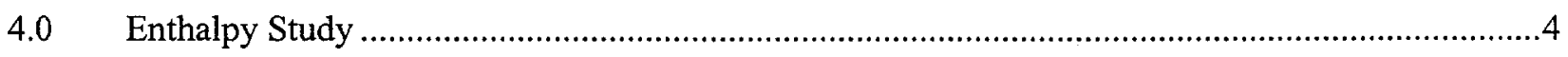

4.1 Calorimeter and Heat Capacity Determination ...............................................................

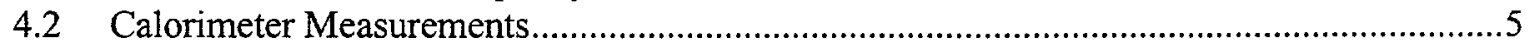

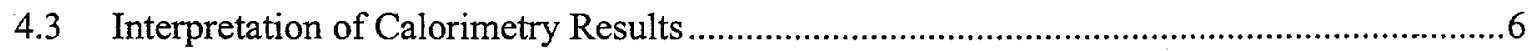

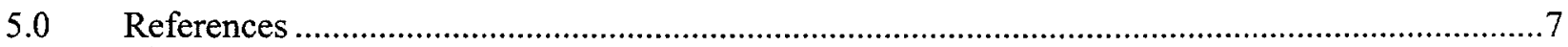

Figures

1 Photographs from Wet Scale Sieving of the FE-1 Composite ................................................

2 Photographs from Wet Scale Sieving of the FE-3 Composite .............................................

3 Photographs from Wet Scale Sieving of the FE-5 Composite ...............................................10

4 Calorimeter Used for Enthalpy of Dissolution Tests..........................................................11

5 Temperature Versus Time for Addition of Stainless Steel Coupons to Calorimeter....................12

$6 \quad$ Acid-Insoluble Residues Following Enthalpy Measurements in 16 M Nitric Acid .....................13

$7 \quad$ Temperature Versus Time for Dissolution of Samples from FE-1 ........................................14

$8 \quad$ Temperature Versus Time for Dissolution of Samples from FE-3 ............................................15

9 Temperature Versus Time for Dissolution of Samples from FE-5........................................16

10 Temperature Versus Time for Dissolution of Sample from FE-6 .........................................17 


\section{Tables}

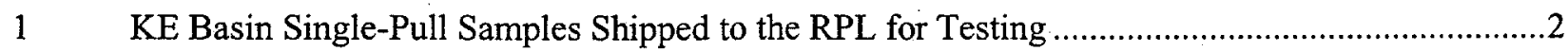

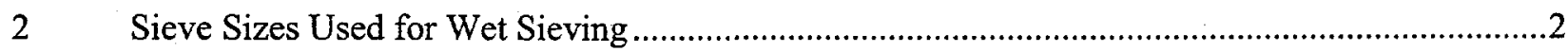

3 Weight Percent Wet Solids Separated by Sieve Size During the Sieving Analysis .......................3

4 Weight Percent Dry Solids Separated by Sieve Size During the Sieving Analysis ......................4

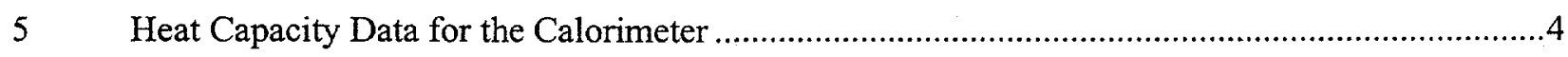

6 Weight Percent Water for the KE Basin Single-Pull Samples Used for Calorimetric Testing ........5

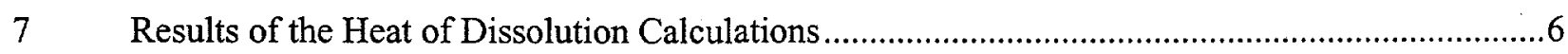




\subsection{Introduction}

This report discusses particle size and calorimetry analyses performed on single-pull sludge samples collected from the Hanford K East Basin floor and pits. This study was conducted by Pacific Northwest National Laboratory (PNNL) in support of the baseline sludge management plan, which calls for the sludge to be packaged, shipped, and stored at T Plant in the Hanford 200 West Area until final processing at a future date. As many of the areas in the $\mathrm{K}$ East Basin represented by the single-pull samples had not been previously sampled, these analyses were needed to better understand the K Basin sludge inventory and chemical reactivity.

Particle size analyses were performed by sieving, a technique by which particles within a material are separated into unique particle size fractions using meshes or perforated membranes. Particle size will dictate the makeup of most of the $\mathrm{K}$ Basin sludge process streams; consequently, knowledge of the particle size distribution is necessary to project the inventory of the various streams. Additionally, the particle size will affect the performance of all physical unit operations included within the sludge management system (e.g., retrieval, transportation, settling). Along with the uranium metal content, particle size will largely determine the chemical reactivity of the sludge.

Dissolution calorimetry tests were conducted with an adiabatic calorimeter to estimate the total metallic uranium content of the single-pull samples. The uranium metal content of the sludge is needed to calculate the quantity and rate of heat and hydrogen gas that can be generated from oxidation reactions during sludge transport and storage.

\subsection{Sample History and Preparation for Analysis}

The KE Basin floor and pit sludge was originally collected between December 1998 and June 1999 with single-pull sampling equipment, where isolated cores of sludge were suctioned into 4-L bottles. The samples were shipped to the Hanford 222-S Laboratory in the 200 West Area for characterization. Following receipt at 222-S, six composites were prepared (FE-1, FE-3, FE-4, FE-5, FE-6, and FE-7) by combining the solids in the sample bottles. Details on the original sampling event can be found in Pitner (1999).

In May 2000, five of the single-pull composites (FE-1, FE-3, FE-4, FE-5, and FE-6) were transferred to PNNL's Radiochemical Processing Laboratory (RPL). Table 1 lists the five composites shipped to the RPL and identifies the original sample bottles used for each composite. With the exception of sample FE-4, all samples received at the RPL contained settled sludge with standing liquid. Sample FE-4 was received as moist solids, but with no standing water. During testing with KE Basin consolidated sludge samples, detailed in Bredt et al. (1999), a KE Basin supernatant composite was prepared from the standing liquid in consolidated floor sludge samples $\mathrm{KC}-4$ and $\mathrm{KC}-5$. Liquid from this supernatant composite was added to FE-4 to generate a wet slurry with standing liquid. Following receipt at the RPL, all $\mathrm{FE}$ composite samples were maintained with a standing liquid layer. 
Table 1. KE Basin Single-Pull Samples Shipped to the RPL for Testing

\begin{tabular}{|c|c|c|}
\hline Composite & $\begin{array}{l}\text { Original Sample } \\
\text { Bottle ID }\end{array}$ & KE Area Represented \\
\hline \multirow{2}{*}{$\begin{array}{c}\text { FE-1 } \\
\text { Main Floor }\end{array}$} & $\begin{array}{l}\mathrm{KE}-1-\mathrm{A}, \mathrm{KE}-1-\mathrm{B} \\
\mathrm{KE}-1-\mathrm{D}, \mathrm{KE}-1-\mathrm{E}\end{array}$ & $\begin{array}{l}\text { East Bay, Cubicle } 0168 \\
\text { South Side, Empty Cubicle }\end{array}$ \\
\hline & KE-2-A, KE-2-B & East Bay, Cub. 1065 , N. side \\
\hline \multirow{2}{*}{$\begin{array}{c}\text { FE-3 } \\
\text { North Loadout } \\
\text { Pit }\end{array}$} & $\begin{array}{l}\text { KE-5-A, KE-5-B, } \\
\text { KE-5-D, KE-5-E }\end{array}$ & $\begin{array}{l}\text { North Loadout Pit (NLOP) } \\
\text { Center }\end{array}$ \\
\hline & $\mathrm{KE}-6-\mathrm{A}, \mathrm{KE}-6-\mathrm{B}$ & NLOP, mid Transfer Channel \\
\hline \multirow{2}{*}{$\begin{array}{c}\text { FE-4 } \\
\text { Dummy Elevator } \\
\text { Pit }\end{array}$} & $\mathrm{KE}-7-\mathrm{A}, \mathrm{KE}-7-\mathrm{B}$ & Dummy Elevator Pit, East \\
\hline & $\begin{array}{l}\text { KE-8-A, KE-8-B, } \\
\text { KE-8-D }\end{array}$ & Dummy Elevator Pit, West \\
\hline \multirow{2}{*}{$\begin{array}{c}\text { FE-5 } \\
\text { Weasel Pit }\end{array}$} & $\begin{array}{l}\text { KE-9-A, KE-9-B, } \\
\text { KE-9-D, KE-9-E }\end{array}$ & $\begin{array}{l}\text { Weasel Pit, Near South Wall, } \\
8 \mathrm{ft} \text { from East End }\end{array}$ \\
\hline & $\begin{array}{l}\text { KE-10-A, KE-10-B, } \\
\text { KE-10-D, KE-10-E }\end{array}$ & $\begin{array}{l}\text { Weasel Pit, Near Center, } 11 \mathrm{ft} \\
\text { from West End }\end{array}$ \\
\hline $\begin{array}{c}\text { FE-6 } \\
\text { Tech View Pit }\end{array}$ & $\mathrm{KE}-11-\mathrm{A}, \mathrm{KE}-11-\mathrm{B}$ & $\begin{array}{l}\text { Just East of Channel to View } \\
\text { Pit }\end{array}$ \\
\hline
\end{tabular}

\subsection{Small-Scale Wet Sieving}

Samples of material from composites FE-1, FE-3, and FE-5 were sieved to characterize the particle size distribution in the sludges. The wet sieving procedure used in this work was adapted from ASTM D546, "Sieve Analysis of Mineral Filler for Road and Paving Materials," with minor deviations such as drying the material at $60^{\circ} \mathrm{C}$ after sieving instead of $110^{\circ} \mathrm{C}$ and using deionized water instead of tap water as the aqueous fluid. Table 2 lists the Tyler sieve sizes used, along with the U.S.A size equivalents and sieve openings. All sieves used in this work were stainless steel and manufactured by W.S. Tyler in conformance to ASTM E11, ANSI, and ISO 565 3310-1 standards.

Table 2. Sieve Sizes Used for Wet Sieving

\begin{tabular}{|c|c|c|c|}
\hline Tyler Size & U.S.A. Equivalent & $\begin{array}{c}\text { Sieve Opening } \\
\text { (in.) }\end{array}$ & $\begin{array}{c}\text { Sieve Opening } \\
\text { (mm) }\end{array}$ \\
\hline 5 & 5 & 0.157 & 4.00 \\
\hline 12 & 14 & 0.0555 & 1.41 \\
\hline 32 & 35 & 0.0197 & 0.500 \\
\hline 60 & 60 & 0.0098 & 0.250 \\
\hline
\end{tabular}

The sieve set was nested with the Tyler 5 on top followed by the Tyler 12, Tyler 32, and Tyler 60, and was placed on a stainless steel bottom pan equipped with a drain running to a $250-\mathrm{ml}$ receiver jar. The preweighed subsample was rinsed onto the Tyler 5 sieve using KE Basin supernatant from the respective canister. Deionized water was then used to rinse as much of the sample as possible through the meshes. A remote video camera, providing color images, was used to inspect the mesh and determine when all particles remaining on the sieve exceeded the mesh size. The sieve was then removed, and the material 
on the next sieve rinsed in the same manner. All particles that passed through the Tyler 60 sieve either flowed into the receiver jar or were rinsed into it at the conclusion of sieving.

Following the rinsing step, the material was allowed to air dry on the sieves for approximately 20 min to $1 \mathrm{hr}$. Once the material dried, the sieves were weighed. This mass can include some water that is trapped on the sieves and between the particles. The mass of wet solids in the receiver was then calculated by subtracting the mass of wet material in all of the sieves from the original sample mass. A wt\% wet solids was calculated for each fraction by dividing the mass of the fraction by the mass of the original sample. Table 3 lists the wt\% wet solids separated in each sieve and receiver.

Table 3. Weight Percent Wet Solids Separated by Sieve Size During the Sieving Analysis

\begin{tabular}{|l|c|c|c|c|c|}
\hline Sample & Tyler 5 & Tyler 12 & Tyler 32 & Tyler 60 & Receiver \\
\hline FE-1 & 1 & 29 & 24 & 8 & 38 \\
\hline FE-3 & 13 & 7 & 44 & 27 & 9 \\
\hline FE-5 & 0 & 1 & 20 & 7 & 72 \\
\hline
\end{tabular}

Values have been rounded to the nearest whole integer.

Figures 1 though 3 show the material retained on each of the sieves. These photographs indicate that the FE-1 and FE-5 samples contain similar materials, as both display a relatively uniform mixture of yellow-green, brown, and white particles. The white particles are generally flat and appear to be paint chips. In past work, yellow and green particles have been associated with uranium oxides; however, inorganic data are not available for these fractions.

The FE-3 composite contains a large number of organic ion exchange beads and yellow-green particulates. Organic ion exchange beads have previously been observed in certain KE Basin sludges and have been identified as Purolite NRW-37 Nuclear Grade Mixed Bed Resin (Schmidt et al. 1998). Most of the beads were visible in the Tyler 32 and Tyler 60 meshes [NRW-37 is predominantly between 15 and 40 mesh (Tyler)]. It is also likely that beads are present in the receiver $(<0.250 \mathrm{~mm})$ fraction, but particles below $0.250 \mathrm{~mm}$ are difficult to differentiate from the rest of the fine sludge using the current in-cell video system. The yellow-green particulates in the FE-3 composite appear more translucent than those in the FE-1 and FE-5 samples.

Following wet sieving and air drying, pans were placed under each sieve, and the sieves and pans were transferred to a drying oven at $60^{\circ} \mathrm{C}$. The receiver jars were allowed to settle for approximately 3 days, and then as much standing liquid as possible was decanted. The receiver jars were then transferred to the oven. The materials remained in the oven until a stable mass was reached ( $24 \mathrm{hr})$. A wt\% dry solids was calculated for each fraction by dividing the dry mass of the fraction (i.e., mass of material on each sieve plus mass of material that dropped onto its associated pan) by the sum of the all the dry fractions of the respective sample. Table 4 lists the wt\% dry solids separated in each sieve and receiver.

Comparing Tables 3 and 4 shows significant differences between the wet and dry particle size distributions for sample FE-3. In Table 3, the Tyler 5 sieve appears to have retained $13 \mathrm{wt} \%$ wet solids, while Table 4 shows no dry solids in the Tyler 5 fraction. The Tyler 12 appears to have retained 7 wt $\%$ wet solids but no dry solids. This is the result of water trapped on the sieves and between the particles following air drying. Since only $17 \mathrm{~g}$ of FE-3 were sieved compared to $30-40 \mathrm{~g}$ for FE-1 and FE-5, this 
Table 4. Weight Percent Dry Solids Separated by Sieve Size During the Sieving Analysis

\begin{tabular}{|l|c|c|c|c|c|}
\hline Sample & Tyler 5 & Tyler 12 & Tyler 32 & Tyler 60 & Receiver \\
\hline FE-1 & 0 & 34 & 24 & 7 & 34 \\
\hline FE-3 & 0 & 0 & 50 & 30 & 19 \\
\hline FE-5 & 0 & 2 & 22 & 6 & 70 \\
\hline
\end{tabular}

Values have been rounded to the nearest whole integer.

trapped water had a greater effect on the FE-3 calculations. Figure 2 shows material from FE-3 was retained on the Tyler 5 and 12 meshes but significantly less than on the Tyler 32 and Tyler 60.

\subsection{Enthalpy Study}

The enthalpy data were acquired by dissolving single-pull sludge samples (settled sludge) (FE-1, FE-3, FE-5, and FE-6) in nitric acid in a calibrated adiabatic calorimeter. Dissolution enthalpy data were then used to discriminate between metallic uranium $(-3750 \mathrm{~J} / \mathrm{g}$ in nitric acid) and uranium oxide $(-394 \mathrm{~J} / \mathrm{g}$ in nitric acid). The testing protocols and data reduction methodologies provided in this test procedure were previously employed to determine the enthalpy of dissolution of KW canister sludge (Bredt, P. R., C. H. Delegard, B. M. Thornton, and K. L. Silvers. 1998. Heat of Reaction in Nitric Acid and Oxidation in Boiling Water of Suspended Metal or Hydride Sludge. PNNL Letter Report Number 29317-18 to Numatec Hanford Corporation).

\subsection{Calorimeter and Heat Capacity Determination}

The calorimeter was assembled as shown in Figure 4. A 100-ml glass beaker cut off at the $80-\mathrm{ml}$ mark was used to contain the $16 \mathrm{M}$ nitric acid. The beaker was wrapped in insulating foam and inserted into a glass vacuum dewar flask. The dewar was covered with a piece of foam, and the temperature of the solution in the calorimeter was measured using a type " $T$ " thermocouple. The thermocouple penetrated the foam and into the acid to a fixed depth.

The heat capacity of the calorimeter $(\mathrm{Cp})$ was measured by placing stainless steel coupons, heated to $100^{\circ} \mathrm{C}$, into the calorimeter, and measuring the resulting temperature changes. Three measurements of the heat capacity were made (Table 5). It was assumed that the heat capacity for stainless steel was $0.469 \mathrm{~J} / \mathrm{g}-\mathrm{K}$, and that the heat capacity of the calorimeter and the stainless steel did not change over the temperature range examined. Figure 5 plots the temperature of the calorimeter as a function of time for addition of the coupons.

Table 5. Heat Capacity Data for the Calorimeter

\begin{tabular}{|l|c|c|c|c|}
\hline $\begin{array}{c}\text { Stainless Steel } \\
\text { Coupon }\end{array}$ & Mass $(\mathrm{g})$ & $\mathbf{T}_{2}-\mathbf{T}_{\mathbf{1}}(\mathbf{K})$ & $\begin{array}{c}\text { Final Temp } \\
\left({ }^{\circ} \mathbf{C}\right)\end{array}$ & $\mathbf{C p}(\mathbf{J} / \mathbf{K})$ \\
\hline SS2 & 45.7621 & 6 & 31.1 & 247 \\
\hline SS3 & 45.7094 & 6 & 32.2 & 242 \\
\hline SS4 & 45.9768 & 5.6 & 30.8 & 267 \\
\hline Average & & 252 \\
\hline Standard Deviation & & 33 \\
\hline
\end{tabular}




\subsection{Calorimeter Measurements}

The initial weight percent water for each composite was determined by loading duplicate aliquots of settled sludge samples FE-1, FE-3, FE-5, and FE-6 $(\sim 0.5 \mathrm{~g})$ into glass thimbles. The thimbles were then placed in an oven at $105^{\circ} \mathrm{C}$ until a stable mass was reached. All mass loss at $105^{\circ} \mathrm{C}$ was assumed to be water. Table 6 lists the weight percent water determined for each sample.

Table 6. Weight Percent Water for the KE Basin Single-Pull Samples (Settled Sludge) Used for Calorimetric Testing

\begin{tabular}{|l|c|c|c|}
\hline \multirow{2}{*}{ Sample } & \multicolumn{3}{|c|}{ Wt\% Water } \\
\cline { 2 - 4 } & Sample 1 & Sample 2 & Average \\
\hline FE-1 & 70 & 74 & 72 \\
\hline FE-3 & 79 & 80 & 80 \\
\hline FE-5 & 54 & 55 & 54 \\
\hline FE-6 & 68 & NA & 68 \\
\hline
\end{tabular}

NA $=$ No Duplicate.

After the wt\% water samples were collected, fresh samples were loaded into thimbles for the calorimeter. A single thimble was introduced by lifting the foam top, dropping the thimble into the acid, and quickly replacing the foam. The temperature of the calorimeter was then monitored until a stable temperature was reached. The reacted samples were then removed from the calorimeter and inspected to determine if the reaction had reached completion. Photographs of the material during this inspection are presented in Figure 6.

The experiment was conducted in duplicate with FE-1, FE-3, and FE-5 samples. Given the limited amount of material, the FE-6 analysis was conducted on a single sample. Figures 7 through 10 plot the temperature in the calorimeter as a function of time after addition of the sludge samples. The enthalpy of reaction for the sludge on a wet basis was calculated using Equation 1, while the enthalpy of reaction on a dry basis was calculated using Equation 2. The results and associated data are listed in Table 7.

$$
\begin{aligned}
\Delta H_{\text {wet }} & =\frac{-C p\left(T_{2}-T_{1}\right)}{m} \\
\Delta H_{d r y} & =\frac{-C p\left(T_{2}-T_{1}\right)-\Delta H_{d}}{m^{*} f s}
\end{aligned}
$$

Where $\Delta \mathrm{H}_{\text {wet }}$ is the enthalpy of reaction for the wet sludge $(\mathrm{J} / \mathrm{g}$ wet)

$\Delta \mathrm{H}_{\text {dry }}$ is the enthalpy of reaction for the dry sludge ( $\mathrm{J} / \mathrm{g}$ dry)

$\mathrm{Cp}$ is the heat capacity of the calorimeter at constant pressure $\left(\mathrm{J} / \mathrm{g}{ }^{\circ} \mathrm{C}\right)$

$\mathrm{T}_{1}$ is the initial temperature of the calorimeter $\left({ }^{\circ} \mathrm{C}\right)$

$\mathrm{T}_{2}$ is the final temperature of the calorimeter $\left({ }^{\circ} \mathrm{C}\right)$

$\Delta \mathrm{H}_{\mathrm{d}}$ is the heat of dilution for water associated with the wet sludge $(\mathrm{J} / \mathrm{g})$ [correlation taken from $J$.

Phys. Chem. Ref. Data, 11 (Suppl. 2):2-65 (1982)]

$\mathrm{m}$ is the mass of wet sludge $(\mathrm{g})$

and $\mathrm{fs}$ is the weight fraction solids (from Table 6). 
Table 7. Results of the Heat of Dissolution Calculations

\begin{tabular}{|l|c|c|c|c|}
\hline Sample & $\begin{array}{c}\text { Mass } \\
(\mathrm{g})\end{array}$ & $\mathrm{T}_{2}-\mathrm{T}_{1}\left({ }^{\circ} \mathrm{C}\right)$ & $\begin{array}{c}\Delta \mathrm{H}_{\text {wet }} \\
(\mathrm{J} / \mathrm{g} \text { wet })\end{array}$ & $\begin{array}{c}\Delta \mathrm{H}_{\text {dry }} \\
(\mathrm{J} / \mathrm{g} \text { dry })\end{array}$ \\
\hline FE-1 T1 & 1.8078 & 1.9 & -265 & -173 \\
\hline FE-1 T2 & 1.902 & 2.1 & -278 & -222 \\
\hline Average & & -271 & -198 \\
\hline RPD & & 5 & 25 \\
\hline FE-3 T3 & 2.1109 & 2.3 & -274 & -185 \\
\hline FE-3 T4 & 2.6109 & 2 & -193 & 201 \\
\hline Average & & & -234 & 8 \\
\hline RPD & & & 35 & NA \\
\hline FE-5 T5 & 3.6241 & 4.3 & -299 & -303 \\
\hline FE-5 T6 & 3.9592 & 4.2 & -267 & -235 \\
\hline Average & & & -283 & -269 \\
\hline RPD & & & 22 & 25 \\
\hline FE-6 T7 & 3.0139 & 3 & -251 & -157 \\
\hline
\end{tabular}

RPD = Relative Percent Difference.

NA $=$ Not Applicable.

\subsection{Interpretation of Calorimetry Results}

The heat evolved by dissolution of uranium metal in nitric acid has been calculated based on the enthalpies of formation of the participating reactants and products (Swanson et al. 1985). For the reaction carried out in Hanford reprocessing plant fuel dissolvers

$\mathrm{U}_{(\mathrm{s})}+5.5 \mathrm{HNO}_{3(\mathrm{aq})} \rightarrow \mathrm{UO}_{2}\left(\mathrm{NO}_{3}\right)_{2(\mathrm{aq})}+2.25 \mathrm{NO}_{2(\mathrm{~g})}+1.25 \mathrm{NO}_{(\mathrm{g})}+2.75 \mathrm{H}_{2} \mathrm{O}$

the enthalpy (evolved heat) is $-3750 \mathrm{~J} / \mathrm{g}$ uranium $(-213 \mathrm{kcal} / \mathrm{mole}$ uranium). In comparison, the enthalpy of the net reaction to oxidatively dissolve $\mathrm{UO}_{2}$ is roughly $-370 \mathrm{~J} / \mathrm{g} \mathrm{UO}_{2}$. An extensive analysis of the enthalpies of dissolution of uranium metal and $\mathrm{UO}_{2}$ has been presented previously (Bredt et al. Letter Report 29317-18 to Numatec Hanford Corporation on September 28, 1998).

The measured enthalpies of reaction for KE Basin single-pull composites FE-1, FE-5, and FE-6 were $-198,-269$, and $-157 \mathrm{~J} / \mathrm{g}$, respectively. These values are well below the exothermic value for $\mathrm{UO}_{2}$.

Therefore, these results do not suggest the presence of significant uranium metal. The measured enthalpy for sample FE-3 was $8 \mathrm{~J} / \mathrm{g}$. This positive value suggests dissolution of this sample is slightly endothermic. However, there is a strong correlation between the average measured enthalpies in Table 7 and the wt $\%$ water in Table 6 . The correlation shows the higher wt\% water samples yield a less exothermic dissolution. This suggests the calculation used to determine $\Delta H_{d}$ in Equation 2 is probably overestimating the heat of dilution. Since the heat of dilution is comparable to the reaction energies, this overestimation results in an apparent minor endotherm for sample FE-3. Without much reactivity in the sludge aliquots, errors or biases in sampling (e.g., delivering less water than measured, which seems to be the case based solely on the comparison of predicted and observed enthalpy change in the water/sand tests) can drive the sludge-acid reaction enthalpy unexpectedly to positive values. Regardless, this work shows no significant uranium metal content in any of the KE Basin single-pull samples. 


\subsection{References}

Bredt, P. R., J. M. Tingey, and A. J. Schmidt. 1999. Testing and Analysis of Consolidated Sludge Samples from the $105 \mathrm{~K}$ East Basin Floor and Canisters. PNNL-13341, Pacific Northwest National Laboratory, Richland, Washington.

Pitner, A. L. 1999. K East Basin Sludge/Sampling 1999 Campaigns. HNF-4747, Rev. 0, Numatec Hanford Corporation, Richland, Washington.

Schmidt, A. J., G. S. Klinger, and P. R. Bredt. 1998. Evaluation of Ion Exchange Material in K Basin Floor Sludge and Potential Solvents for PCB Extraction from Ion Exchange Materials. PNNL-12108, Pacific Northwest National Laboratory, Richland, Washington.

Swanson, J. L., L. A. Bray, H. E. Kjarmo, J. L. Ryan, C. L. Matsuzaki, S. G. Pitman, and J. H. Haberman. 1985. Laboratory Studies of Shear/Leach Processing of Zircaloy Clad Metallic Uranium Reactor Fuel. PNL-5708, Pacific Northwest National Laboratory, Richland, Washington. 


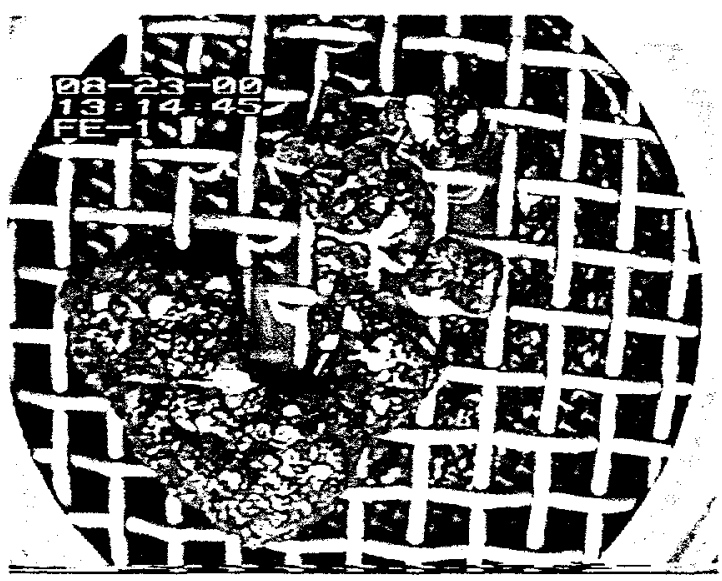

(a)

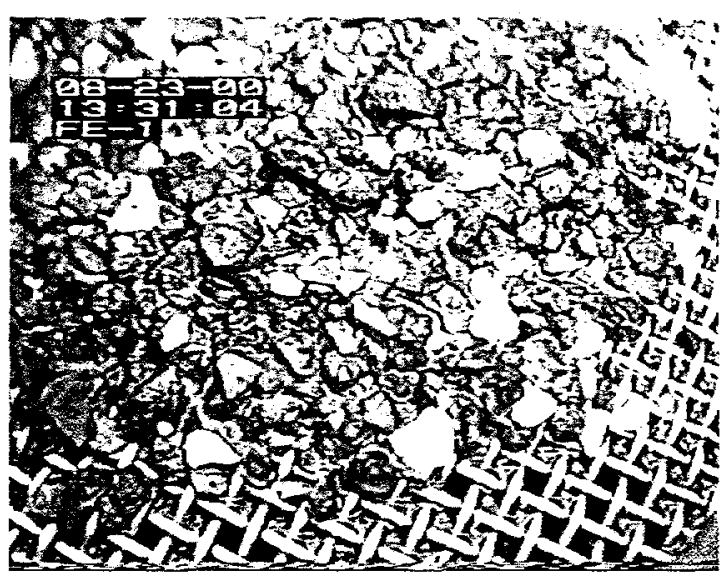

(c)

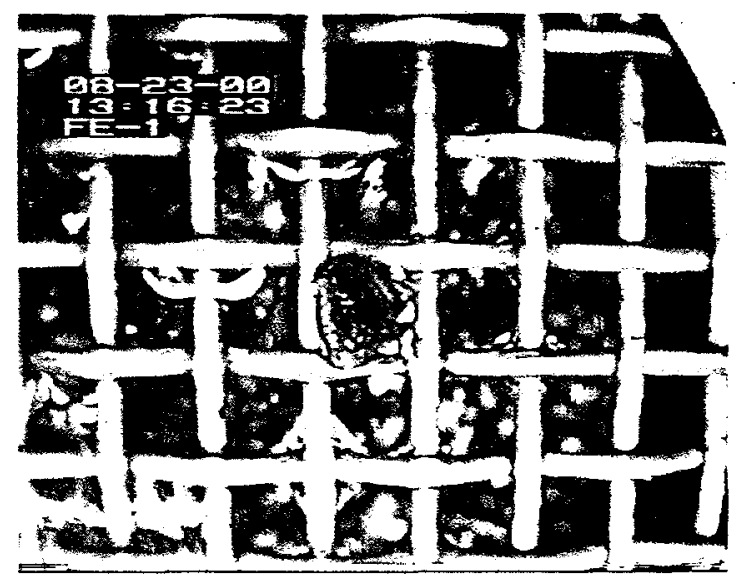

(b)

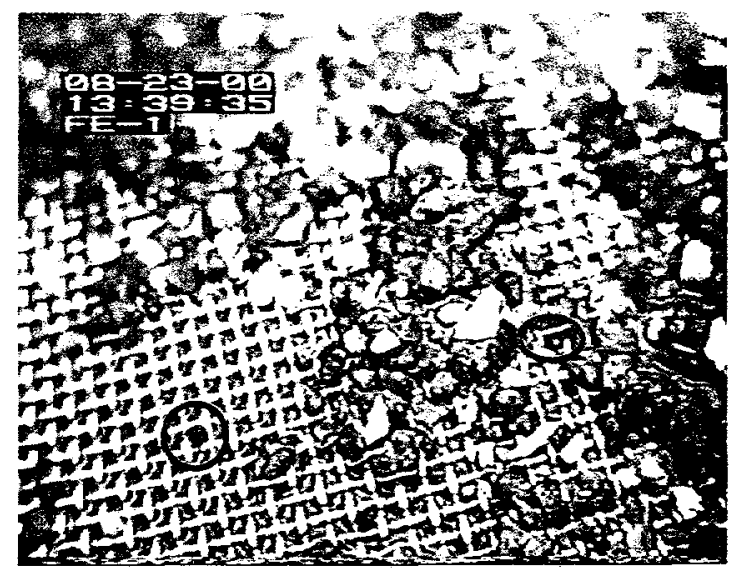

(d)

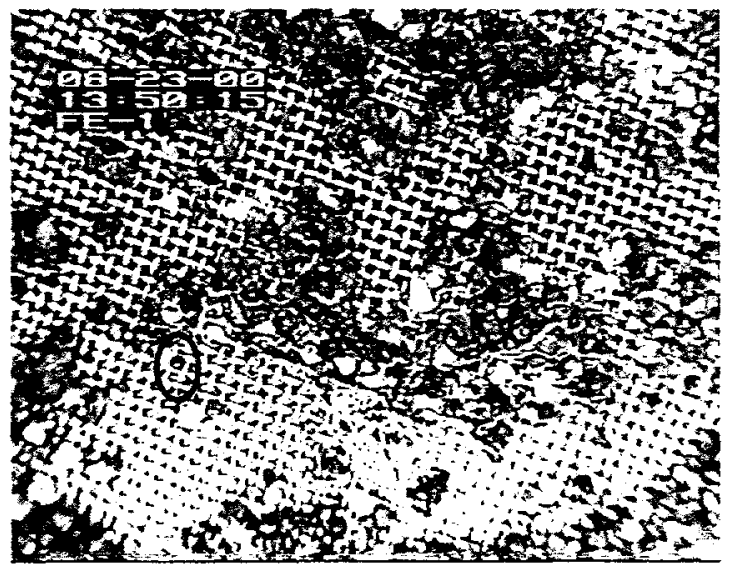

(e)

Figure 1. Photographs from Wet Scale Sieving of the FE-1 Composite.

(a) material on the sieve stack prior to rinsing.

(b) through (e) material retained on the Tyler 5, 12,32 and 60 meshes, respectively.

Several objects that could be resin beads are circled in red. 


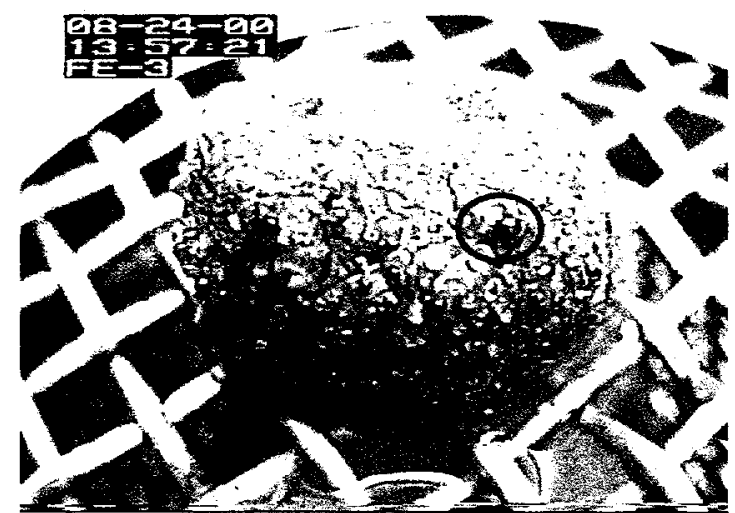

(a)

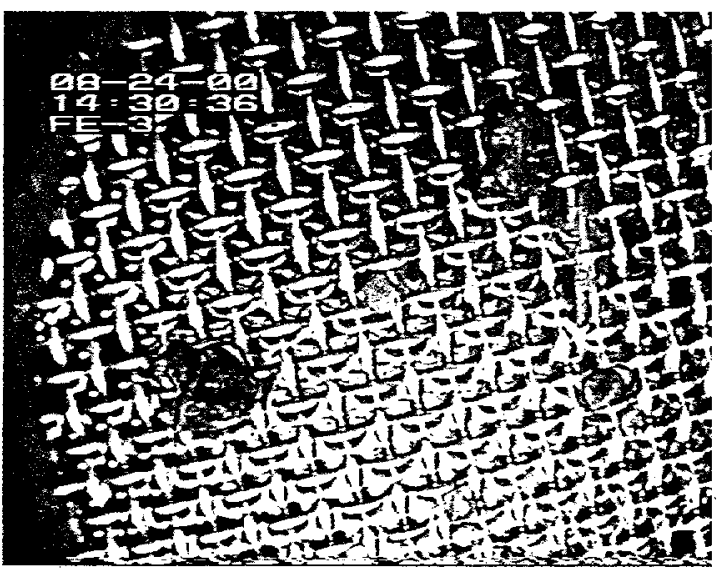

(c)

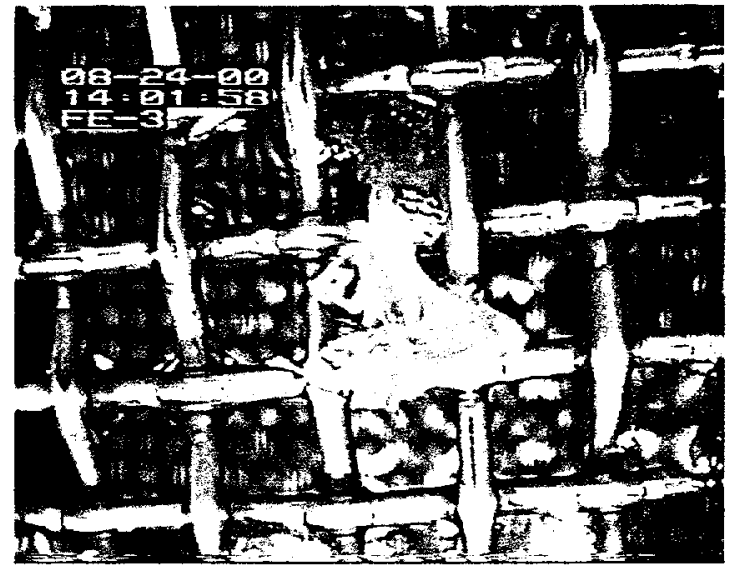

(b)

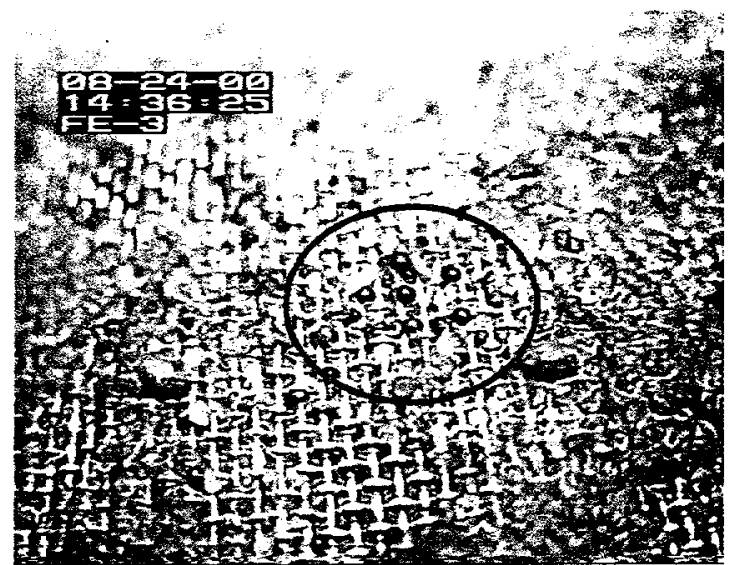

(d)

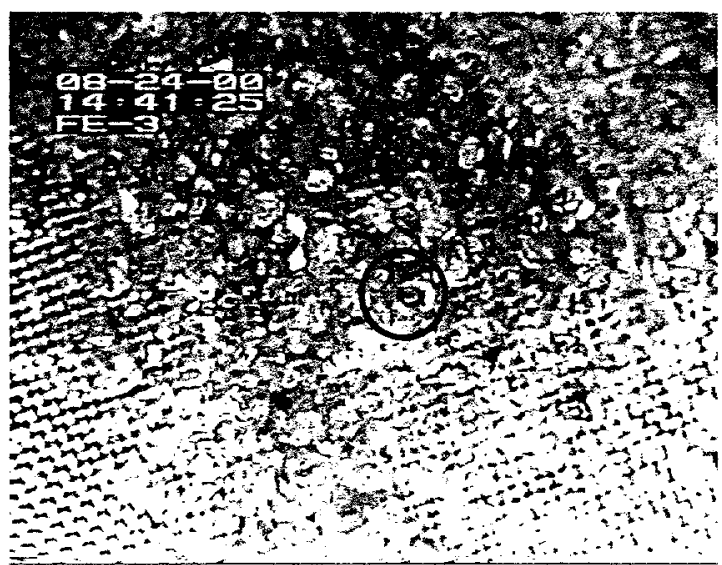

(e)

Figure 2. Photographs from Wet Scale Sieving of the FE-3 Composite.

(a) shows material on the sieve stack prior to rinsing.

(b) through (e) show material retained on the Tyler 5, 12, 32 and 60 meshes, respectively. Several objects that are clearly resin beads are circled in red. 


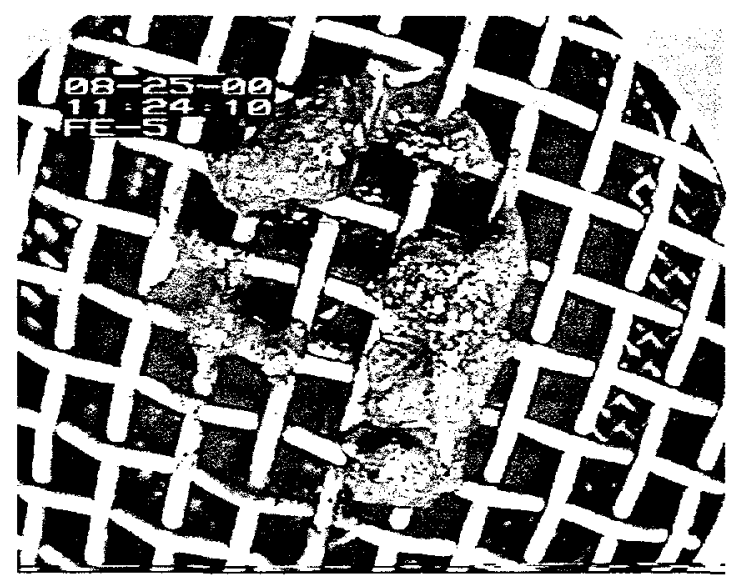

(a)

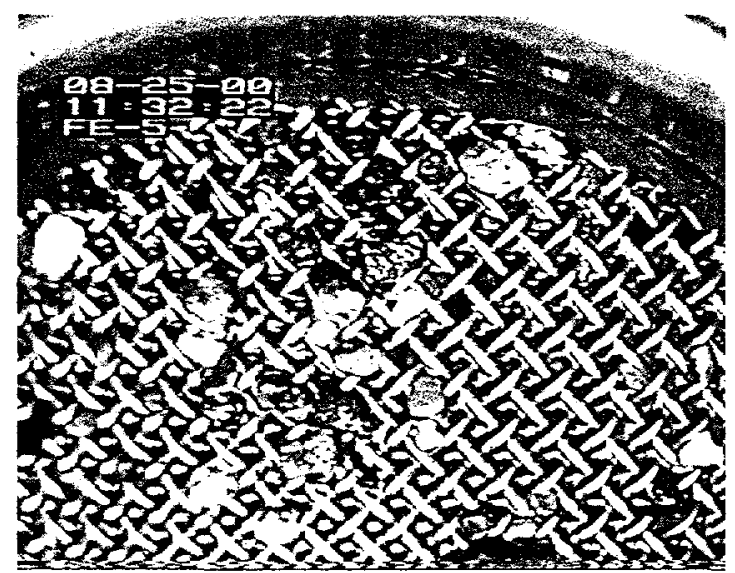

(c)

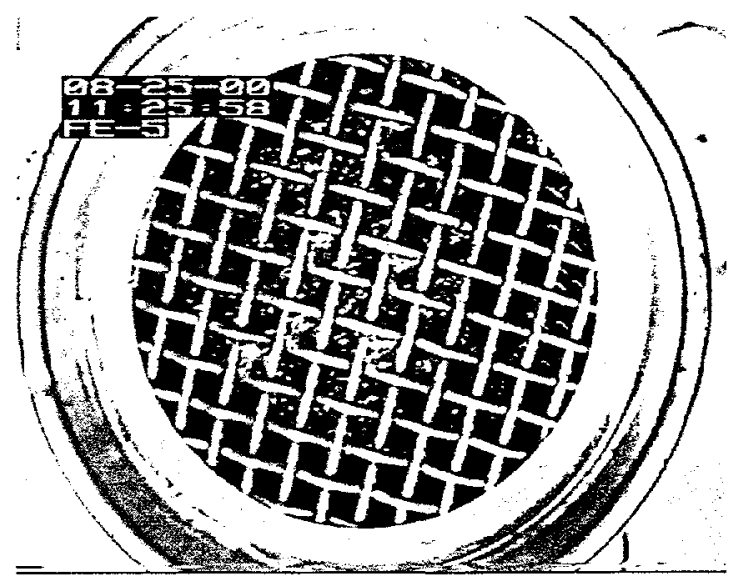

(b)

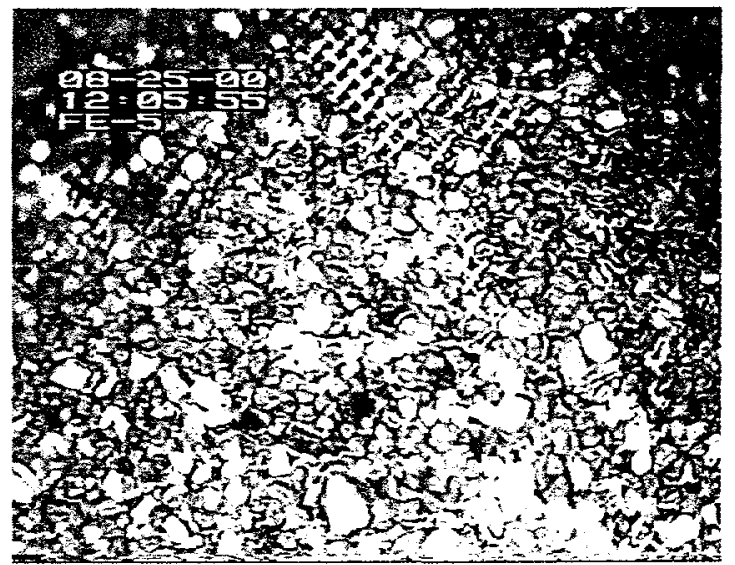

(d)

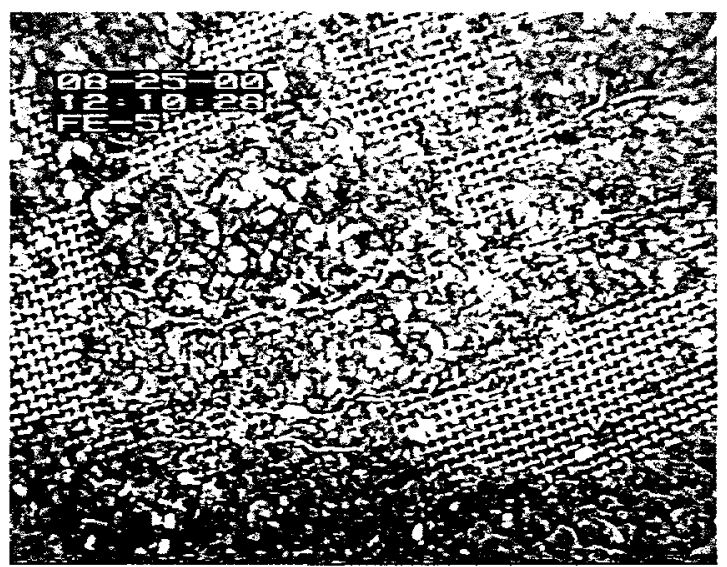

(e)

Figure 3. Photographs from Wet Scale Sieving of the FE-5 Composite.

(a) shows material on the sieve stack prior to rinsing.

(b) through (e) show material retained on the Tyler 5, 12,32 and 60 meshes, respectively. As seen in (b), no material was retained on the Tyler 5 screen. 


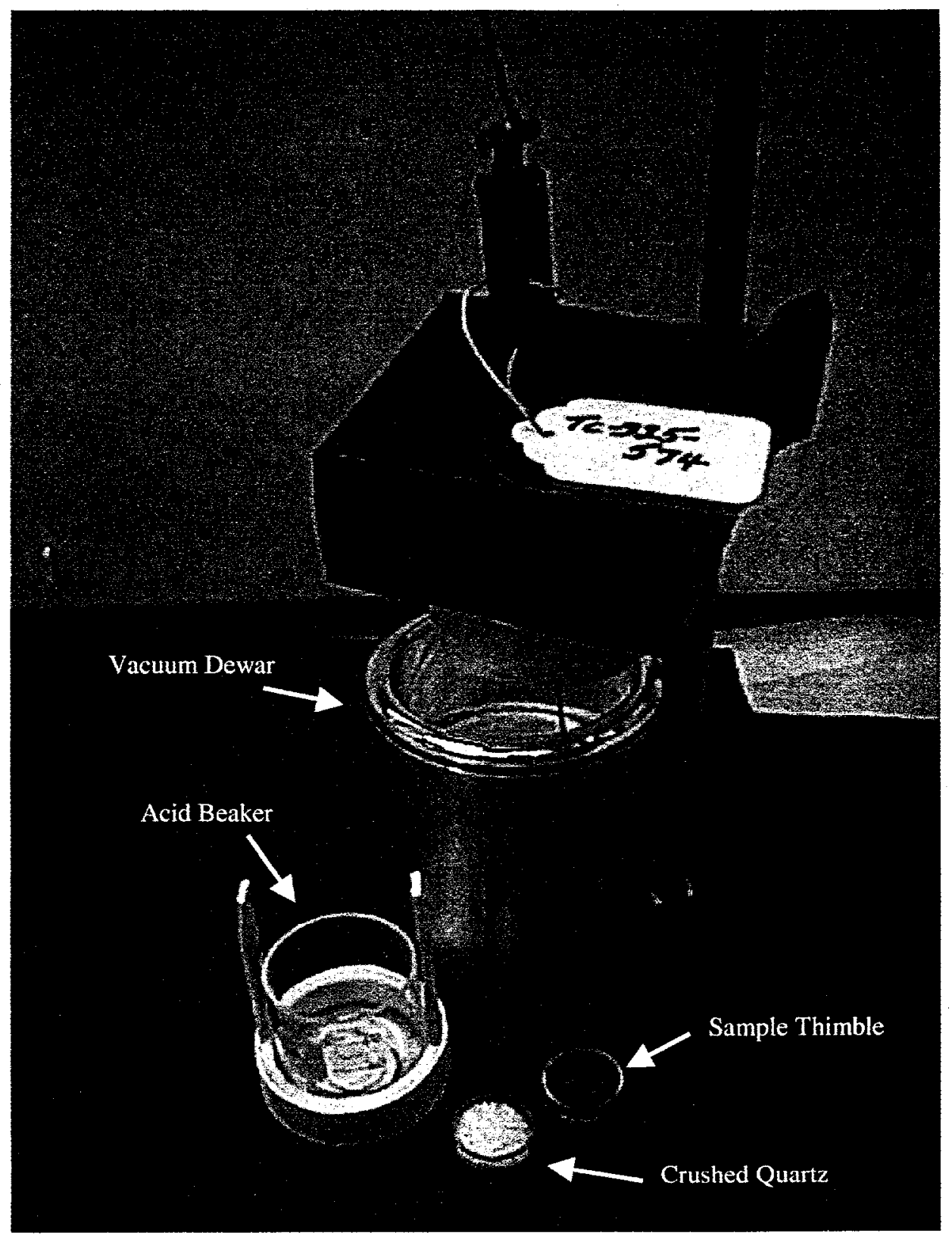

Figure 4. Calorimeter Used for Enthalpy of Dissolution Tests 


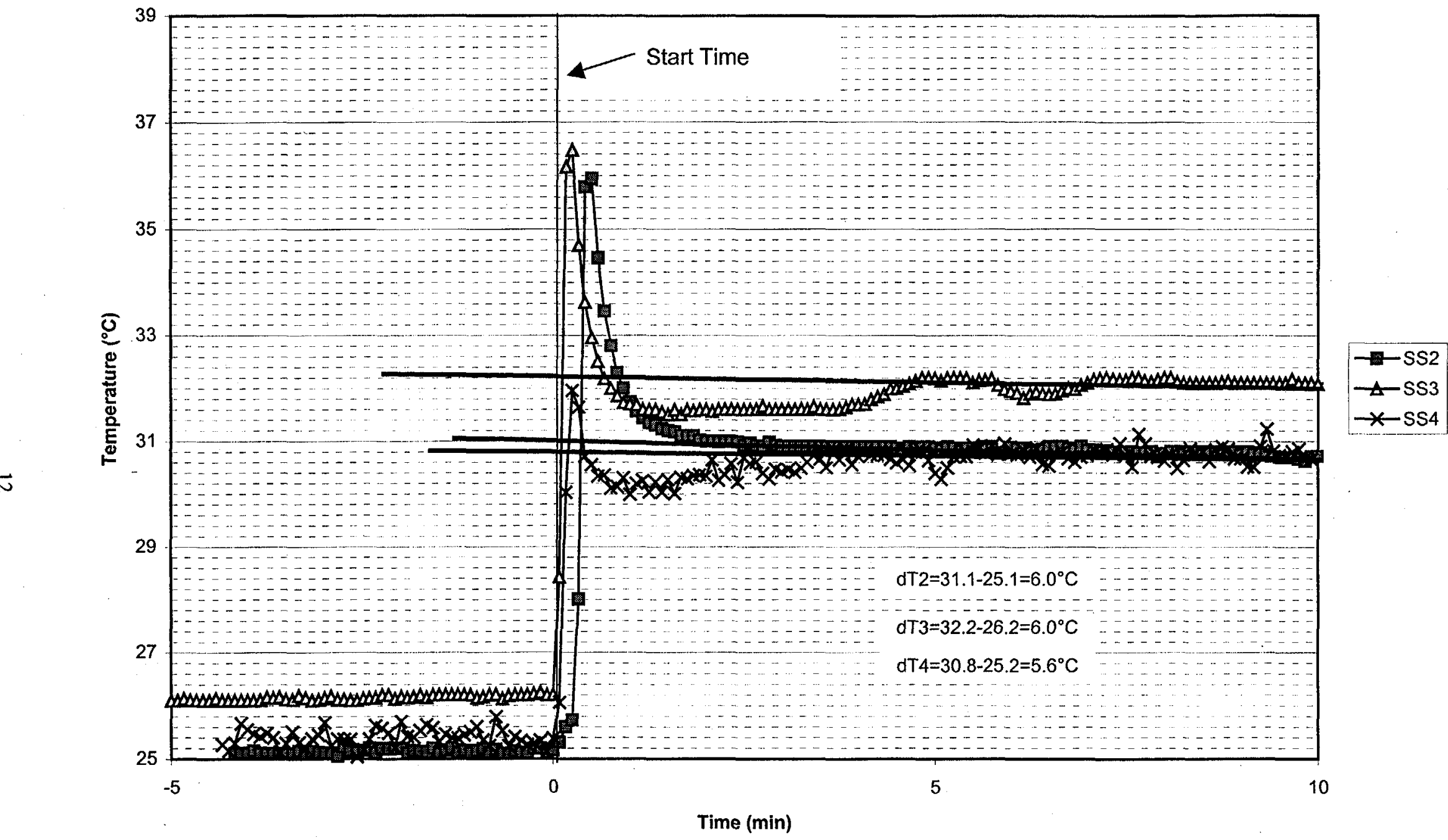

Figure 5. Temperature Versus Time for Addition of Stainless Steel Coupons to Calorimeter 


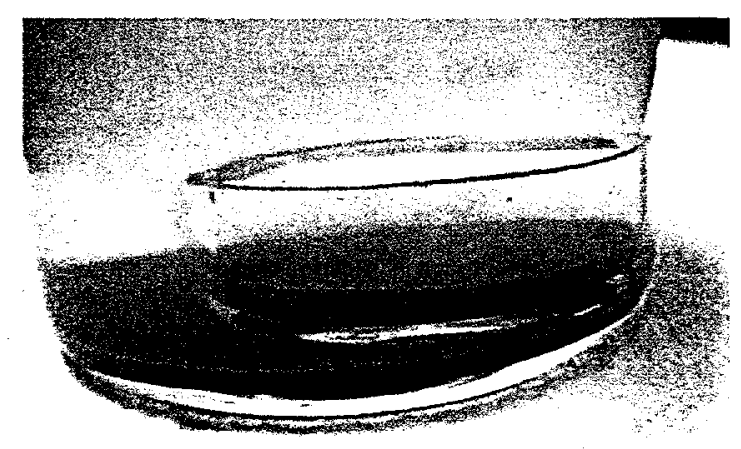

(a)

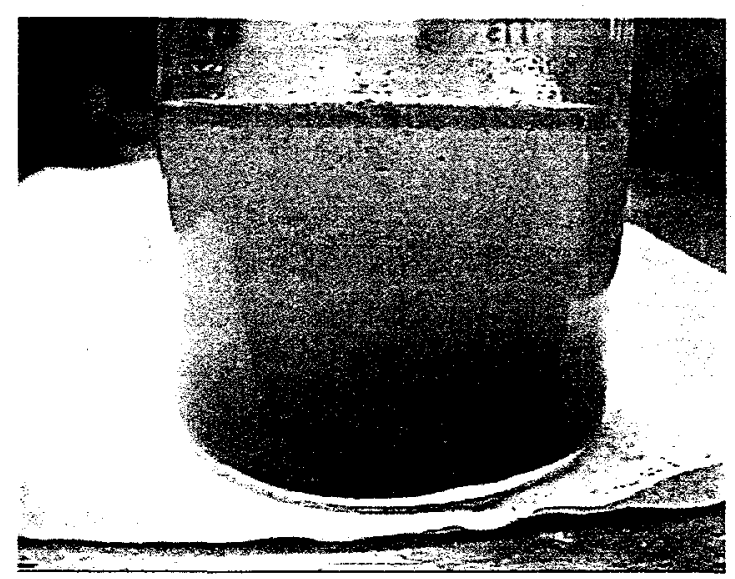

(c)

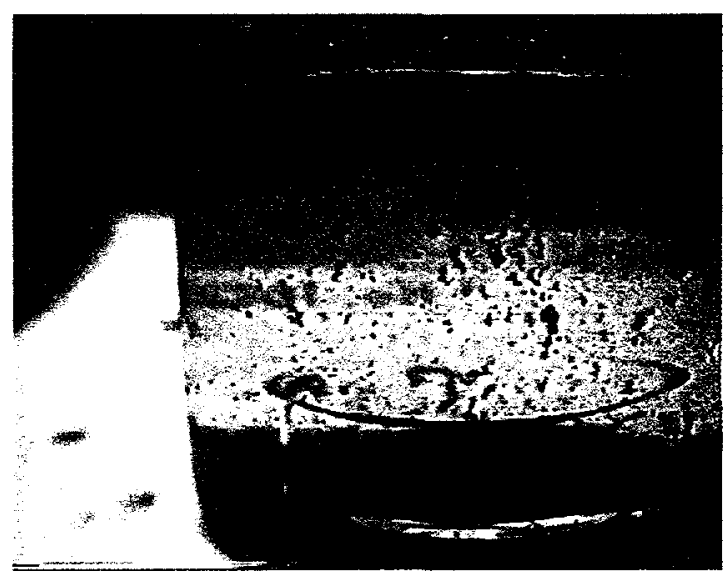

(b)

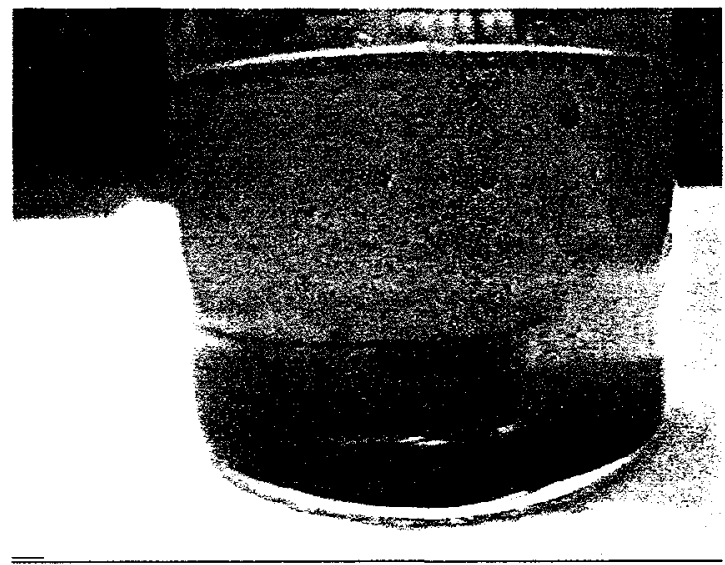

(d)

Figure 6. Acid-Insoluble Residues Following Enthalpy Measurements in $16 \underline{\mathrm{M}}$ Nitric Acid. (a) through (d) are subsamples from FE-1, FE-3, FE-5 and FE-6, respectively. 


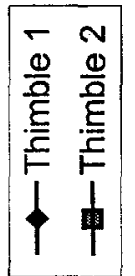

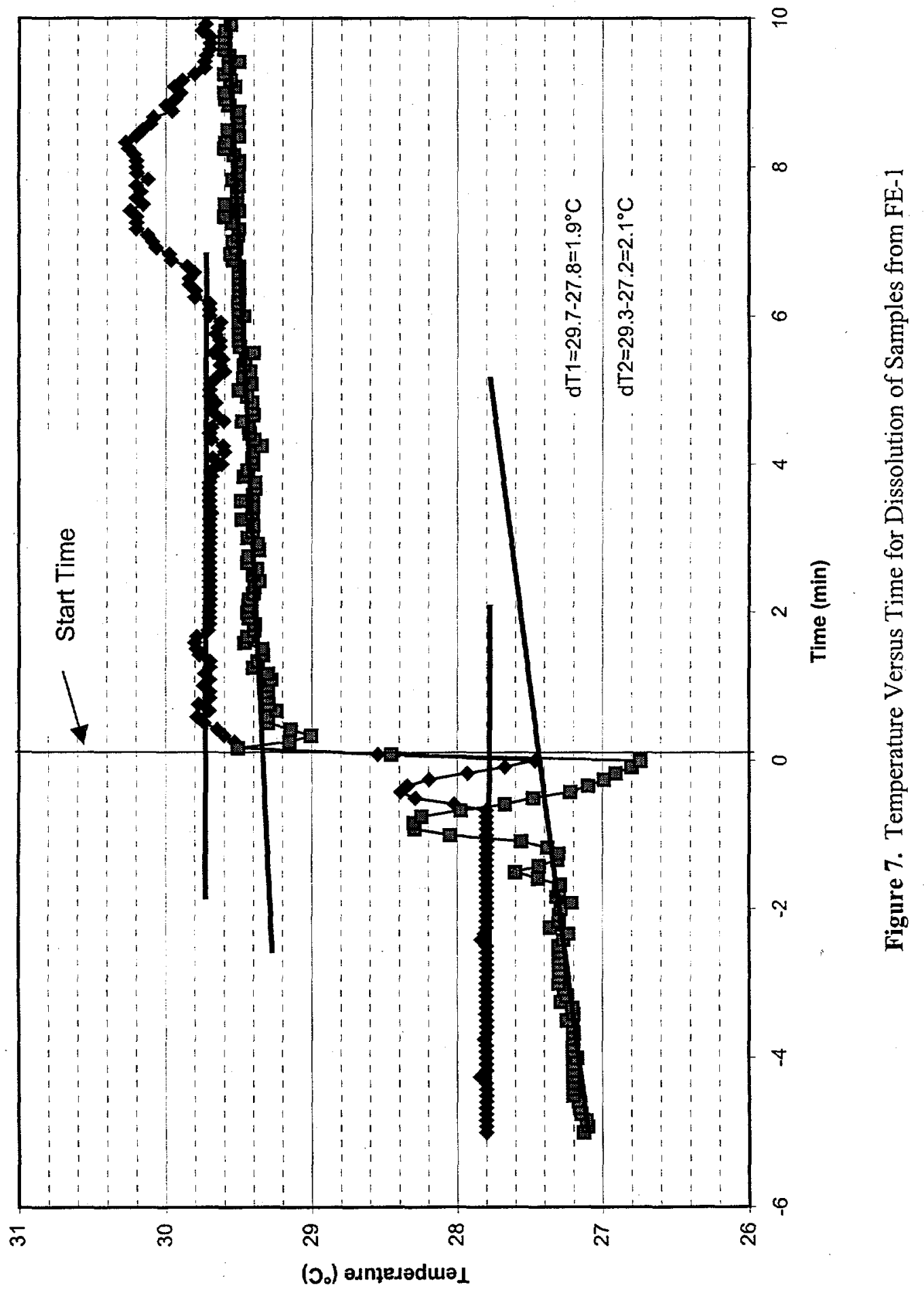




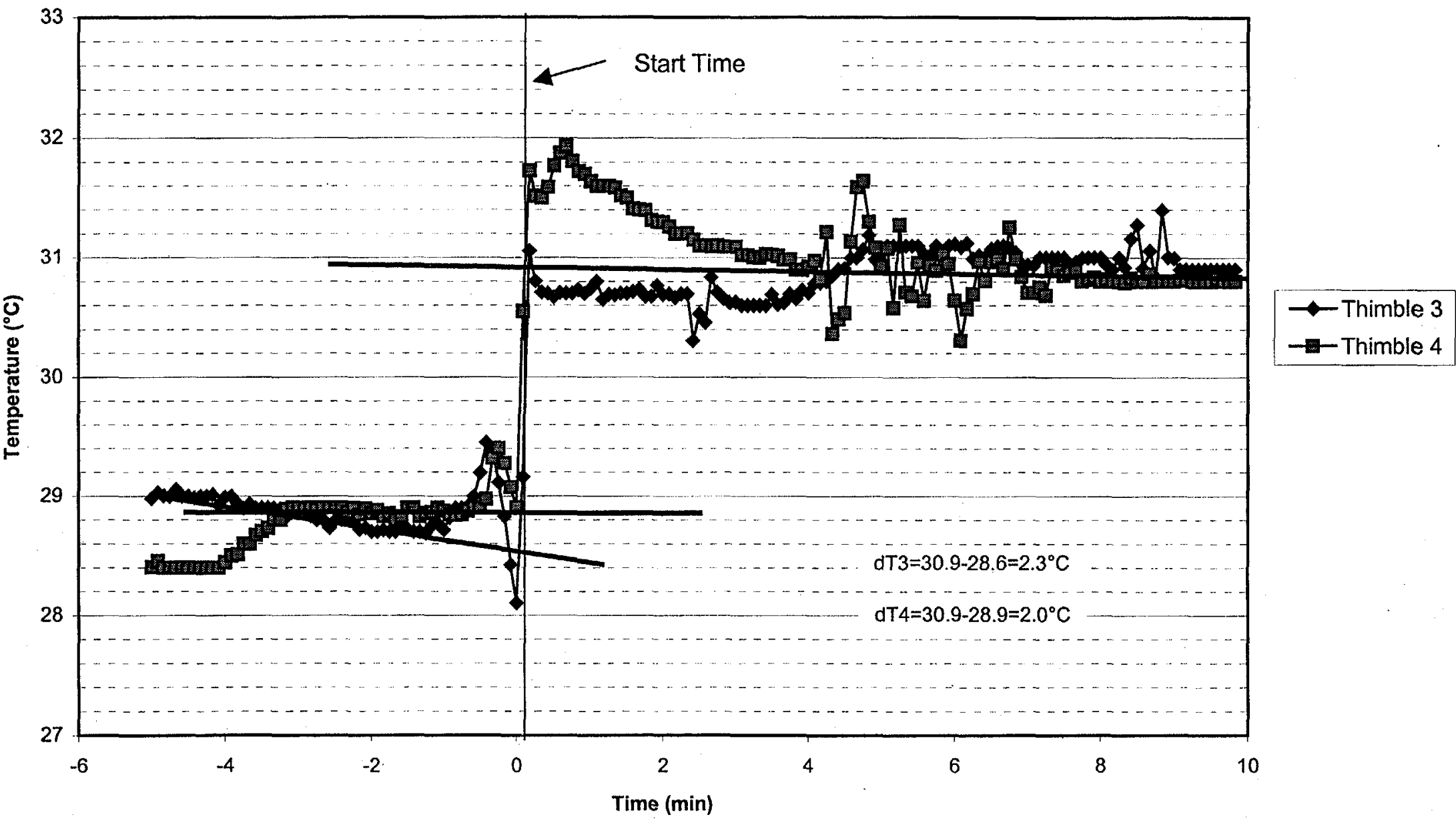

Figure 8. Temperature Versus Time for Dissolution of Samples from FE-3 


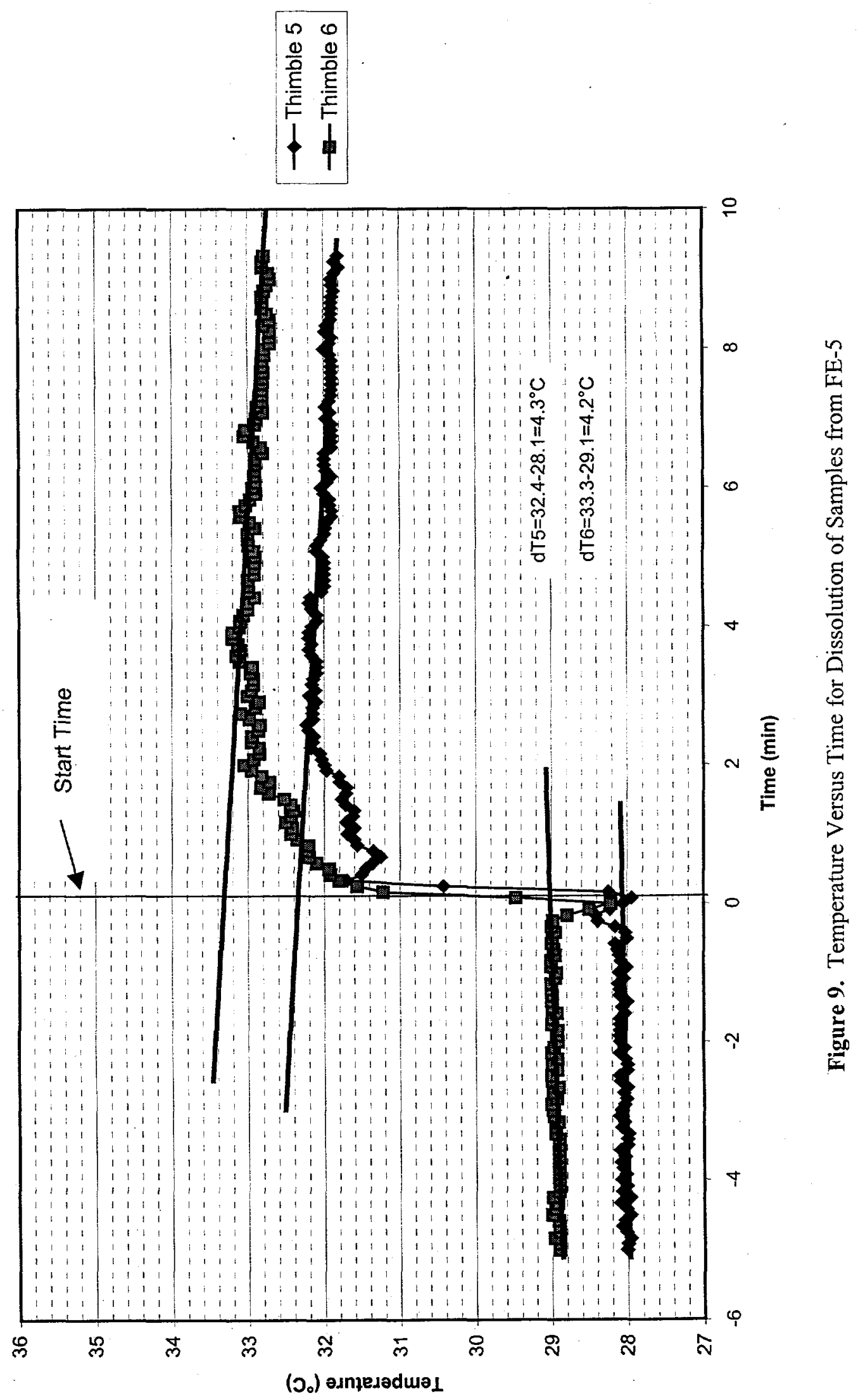




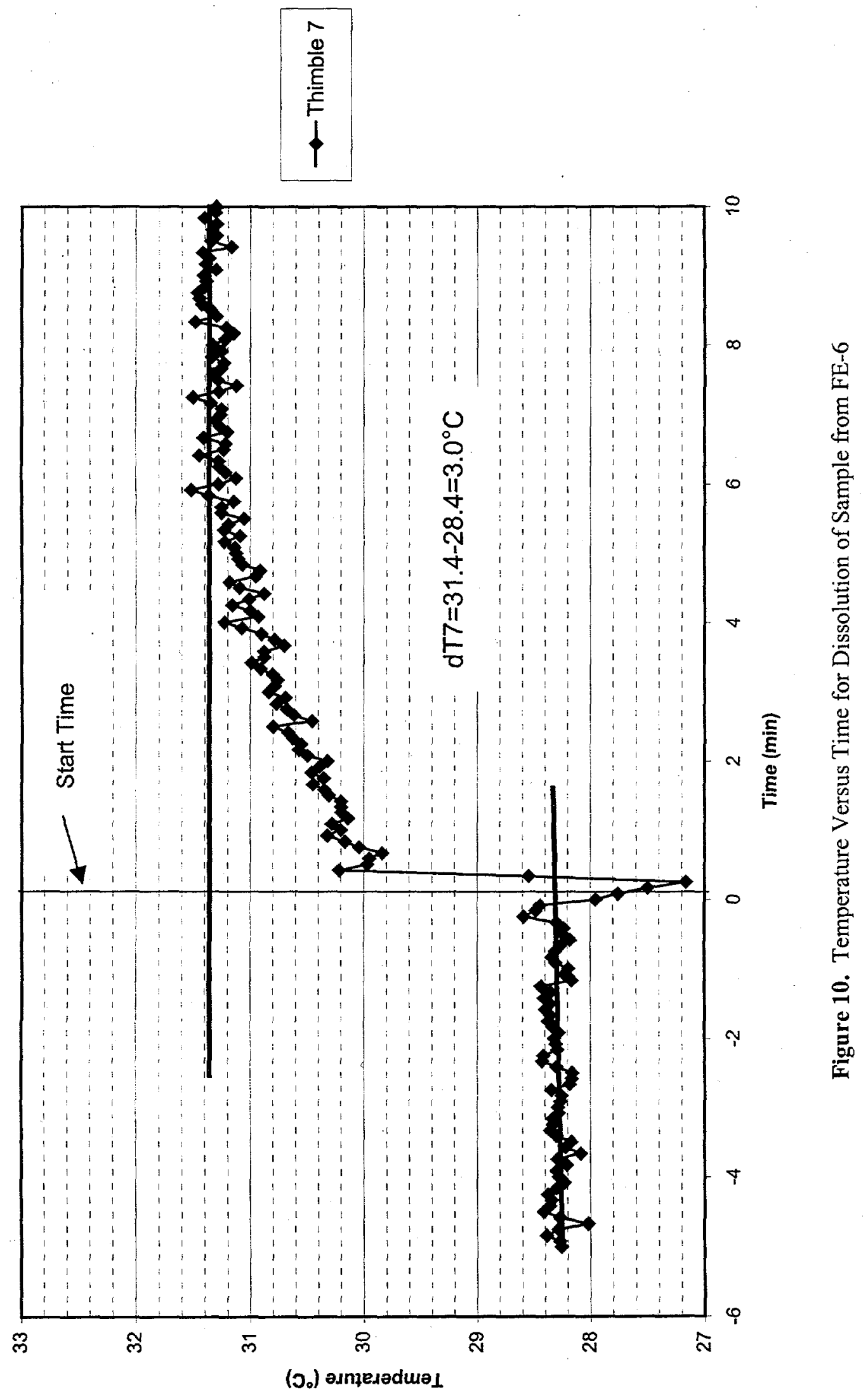

